ORIGINAL ARTICLE

\title{
Worse lung cancer outcome in patients with lower respiratory tract infection confirmed at time of diagnosis
}

\author{
Attila Nagy ${ }^{\dagger}$, Veronika Müller ${ }^{\dagger}$, Abigel M. Kolonics-Farkas (D), Noemi Eszes, Krisztina Vincze \& \\ Gabor Horvath
}

Department of Pulmonology, Semmelweis University, Budapest, Hungary

\author{
Keywords \\ Lower respiratory tract infection; lung cancer; \\ survival; treatment. \\ Correspondence \\ Abigel M. Kolonics-Farkas, Department of \\ Pulmonology, Semmelweis University, \\ Budapest 1125, Diósárok u. 1/c, Hungary. \\ Tel: +3613559733 \\ Fax: +3612142498 \\ Email: kolonics-farkas.abigel@ \\ med.semmelweis-univ.hu
}

${ }^{\dagger}$ These authors contributed equally to this work.

Received: 3 June 2019;

Accepted: 5 July 2019.

doi: $10.1111 / 1759-7714.13153$

Thoracic Cancer 10 (2019) 1819-1826

\begin{abstract}
Background: Pulmonary malignancy is one of the most frequent and fatal cancers in older patients. As data on lower respiratory tract infection (LRTI) and the outcome of lung cancer are scarce, our objective was to determine the impact of LRTI on therapeutic possibilities and one-year mortality.

Methods: Patients undergoing bronchoscopy in 2017 who had bronchial microbial sampling at the time of the lung cancer diagnosis $(n=143)$ were included. Group 1 (LRTI +$)$ included patients with confirmed infection $(n=74)$ while Group 2 (LRTI-) included patients without infection $(n=69)$. Clinical characteristics, pathogen profile and one-year survival were analyzed.

Results: Age, gender, TNM stage, histology type, comorbidities or underlying lung disease did not differ among groups. The most common LRTI pathogens included aerobic $(n=49)$, anaerobic $(n=14)$ and fungal $(n=26)$ infections. Chemo/immune/target therapy alone, or in combination with radiotherapy were significantly less frequently used, whilst palliative care was more common in Group 1 (LRTI+). Multiple pathogen LRTI patients were significantly older, less frequently diagnosed with adenocarcinoma and had worse performance status compared to solitary pathogen LRTI patients. One-year median survival was 274 days ( 235 vs. 305 days Group 1 vs. Group 2). Risk factors for increased one-year mortality included performance status $\geq 2$ (OR 30.00, CI 95\% 5.23-313.00), performance status 1 (OR 11.87, CI 95\% 4.12-33.78), male gender (OR 4.04, CI 2.03-8.04), LRTI with multiple pathogens (OR 2.72, CI 1.01-6.81) and nonadenocarcinoma histology (OR 2.26, CI 1.15-4.56).

Conclusion: LRTIs in lung cancer patients, especially multiple pathogen infections, are associated with less oncotherapeutic possibilities and significant risk for lower one-year median survival.
\end{abstract}

\section{Key Points}

Significant findings of the study

Patients with LRTI less frequently had adencocarcinoma, significantly worse ECOG performance status withholding several treatment possibilities and lower one-year survival. Patients with multiple pathogen LRTI were less eligible for oncotherapy and had significantly increased risk of one-year mortality.

\section{What this study adds}

More attention should be given to LRTI lung cancer patients and the pathogen profile described in our series could assist with empiric treatment selection. Treatable threats are important elements to improve survival of this special patient population.

\section{Introduction}

Lung cancer is one of the leading causes of malignancyassociated mortality worldwide. ${ }^{1}$ The prevalence in older age has risen considerably in the past decade, ${ }^{2}$ with more than 2000000 patients recognized yearly with pulmonary malignancy. ${ }^{3}$ 
Lung cancer is often asymptomatic in the early stages; on the other hand, most cases are diagnosed only when the disease is at an advanced stage. ${ }^{4}$ No established screening strategies are available; however, the results of the NELSON trial, using a low dose $\mathrm{CT}$, are promising for the future. $^{5}$

Advanced disease, older age and comorbidities often make histological verification difficult and may also be associated with less favorable treatment options. ${ }^{6}$ Lung cancer often develops in damaged lungs (e.g., chronic obstructive lung disease, emphysema, idiopathic pulmonary fibrosis [IPF]) and underlying lung diseases might make diagnosis and treatment even more difficult. ${ }^{7.8}$ In addition to lung disease, numerous factors can additionally predispose lung cancer patients to develop lower respiratory tract infection (LRTI), including damage to anatomical barriers during invasive procedures. ${ }^{9}$ With subtle or absent respiratory symptoms, the diagnosis of infection is often delayed, which can readily lead to increased morbidity and mortality especially for elderly individuals. ${ }^{10-12}$

Despite the high mortality rate of lung cancer, additional treatable threats should be considered when treating patients, particularly with extensive disease. In this study, we aimed to determine LRTI in Hungarian lung cancer patients and assess its impact on treatment possibilities and one-year survival.

\section{Methods}

\section{Study population}

The medical records of 966 patients undergoing bronchoscopy at Semmelweis University, Department of Pulmonology in the year 2017 were reviewed. All patients who underwent bronchoscopy for microbiological sampling $(n=648)$ were selected, out of whom all with confirmed pulmonary malignancy $(n=143)$ were included in this retrospective analysis. The selection of the study population is summarized in Fig 1.

Two groups were compared: Group 1, $(n=74)$ consisting of patients with concomitant lower respiratory tract infection (LRTI+) at the time of the diagnosis, and Group 2 (LRTI-; $n=69$ ). Demographic information (age, gender), smoking habits, stage (TNM classification of malignant tumors), body mass index (BMI), underlying lung disease (presence of chronic obstructive pulmonary (COPD) and/or interstitial lung disease (ILD), anatomical localization of the cancer, ECOG (Eastern Cooperative Oncology Group) performance status, comorbidities, peripheral blood neutrophil/lymphocyte ratio (NLR), tumor histology were summarized. Forced vital capacity (FVC), forced expiratory volume in one second $\left.\left(\mathrm{FEV}_{1}\right), \mathrm{FEV}_{1} / \mathrm{FVC}\right)$ was measured by means of electronic spirometer and

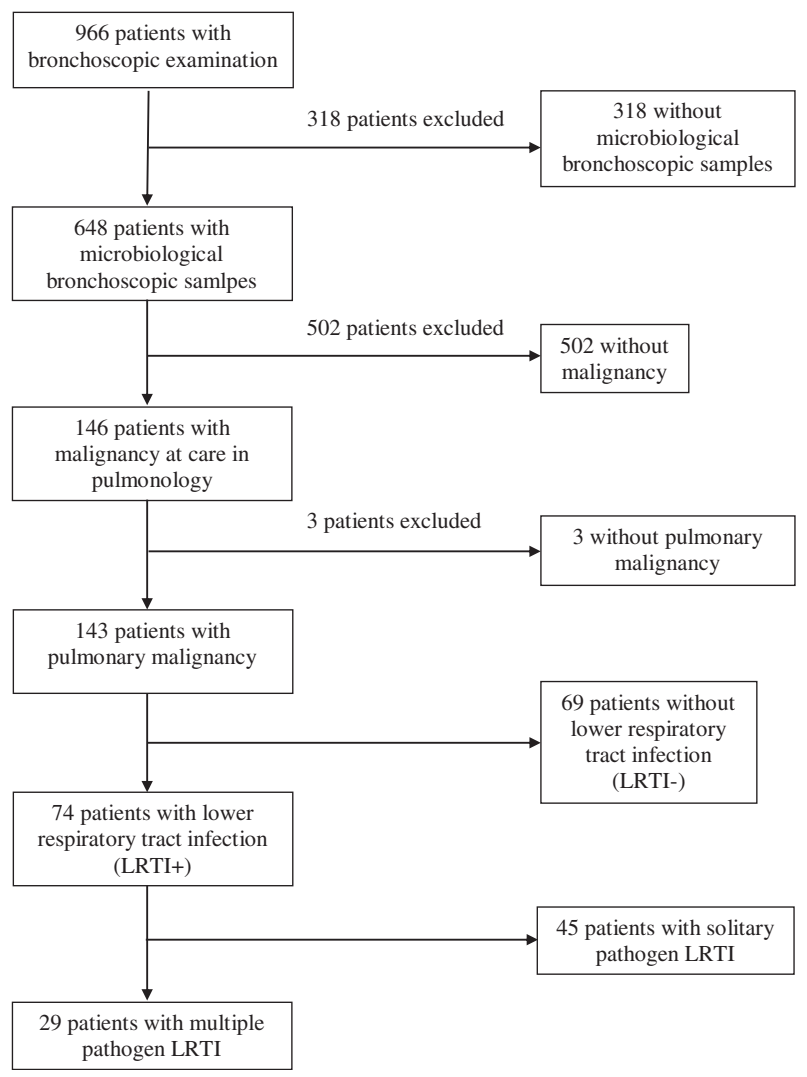

Figure 1 Selection of the study population.

plethysmography (PDD-301/s, Piston, Budapest, Hungary) according to the American Thoracic Society guidelines. ${ }^{13}$ Three technically acceptable maneuvers were performed and the highest used.

Additionally, cancer therapy, including curative intent surgery/radiotherapy, chemotherapy and/or radiotherapy as well as the best supportive care were analyzed. All treatment decisions were made at the multidisciplinary tumor board according to national regulations and ESMO (European Society for Medical Oncology) guidelines. ${ }^{14-16}$ All patients were followed for at least one year. One-year survival was assessed in all patients and the results of the groups were analyzed.

\section{Lower respiratory tract infection}

Bronchoscopies with microbiological test results from bronchial lavage were selected. Microbial analysis was more frequently performed in bronchoscopic procedures in patients with purulent endobronchial mucus, which may have contributed to some extent to selection bias. The samples were analyzed for aerobic and anaerobic bacteria, fungal and Mycobacterium infections. Infections appearing in 
further areas, such as global septicemia or urinary tract infection, were not considered for the current research. LRTI was confirmed when samples contained pathogens of colony forming units (CFU) $\geq 10^{2}$, while lower CFU was considered as potential upper-airway contamination. Infections with samples positive for only one pathogen were acknowledged as solitary pathogen infections. LRTI with at least two microorganisms were determined as multiple pathogen LRTI. All clinical data, oncotherapy and one-year survival were additionally assessed in solitary pathogen and multiple pathogen subgroups of Group 1 (LRTI+).

\section{Statistical analysis}

Data are reported as means \pm SEM or median (range). Statistical analysis was performed with the GraphPad software (Graph Pad Prism 5.0 by Graph Pad Software Inc., San Diego, USA). Normally distributed data were analyzed by an unpaired $t$-test, for categorical data, the Chi-square test was used. Survival was analyzed with the Kaplan Meier test. Risk factors for one-year mortality were calculated with determining odds ratios (Graph Pad Prism 5.0 by Graph Pad Software Inc., San Diego, USA and IBM SPSS, Armonk, New York, USA). $P<0.05$ was considered as statistically significant.

\section{Results}

\section{Baseline characteristics}

Our analysis included slightly more men than women, and these were mostly ever-smokers (Table 1.). Histology distribution, anatomical location, and underlying lung diseases were not different between the groups and TNM stages were similarly distributed. Most of the patients were discovered in more advanced stages, not eligible for curative intent therapies, which was similar in both groups. Most patients had an ECOG performance status of $0-1$; however, we could see significantly more patients with the best performance state in Group 2 (LRTI-). No differences in the number of comorbidities were noted. Significantly higher NLR was observed in Group 1 (LRTI+).

In Group 1 (LRTI+) the pathogen profile is summarized according to the histology type in Table 2. Aerobic, anaerobic and fungal infections did not differ, but significantly more solitary pathogens were noted in adenocarcinoma patients. Most common solitary pathogens in Group 1 (LRTI+) included Candida albicans $(n=19)$, $H$. influenzae $(n=15), S$. aureus $(n=13)$, S. pneumoniae $(n=10)$, Enterobacter spp. $(n=10), P$. aeruginosa $(n=7)$ and other pathogens $(n=42)$. Isolates of multiple pathogen LRTI were similarly distributed, and included Candida albicans $(n=14), S$. pneumoniae $(n=7)$, S. aureus $(n=7)$,
$P$. aeruginosa $(n=6), H$. influenzae $(n=6)$ and other pathogens $(n=31)$; although there were proportionally more Candida albicans, $S$. pneumonia and P. aeruginosa infections detected. The percentage of $H$. influenzae was notably lower than in the solitary pathogen LRTI individuals $(8.45 \%$ vs. $20 \%)$.

Oncotherapy possibilities are summarized in Table 3. Curative intent interventions were not different between groups; less than $15 \%$ were eligible. Chemo/immune/target therapy alone or in combination with radiotherapy were significantly less frequent in Group 1 (LRTI+) as compared to Group 2 (LRTI-). Conversely, significantly more patients in Group 1 (LRTI+) could only receive the best supportive care (BSC) as compared to Group 2 (LRTI-). In general, nearly one-quarter of the patients were not eligible for palliative oncotherapeutic interventions.

The one-year median survival for all patients was 274 days, lower for Group 1 (LRTI+) with 235 days as compared to Group 2 (LRTI-) where it was 305 days. Kaplan Meier analysis did not show any statistically significant differences between the groups $(P=0.244$, HR: 1292 [95\% CI: 0.84-1.99], Fig 2).

Between the subgroups, made according to the presence of solitary or multiple pathogens, patients in the latter group were significantly older and had worse ECOG performance status (Table 1). Significantly less adenocarcinoma was noted in this subgroup and the curative intent interventions were less common in these cases. Significantly more patients could only receive BSC compared to solitary pathogen LRTI (Table 1). Lung cancer patients with solitary pathogen LRTI had longer median one-year survival as compared to patients with multiple pathogens (306 vs. 146 days, HR: 1.57 [95\% CI: 0.87-2.99], $P=0,318$; Fig 2). Patients with multiple pathogen infections had shorter median one-year survival than lung cancer patients in Group 2 (LRTI-) (146 vs. 305 days, HR: 1.67 [95\% CI: $0.98-3.23$ ], $P=0.057)$.

Odds ratio analysis data are presented in Table 4. Significantly higher risk could be observed for one-year mortality in case of performance status $\geq 2$, male gender, LRTI with multiple pathogens and nonadenocarcinoma histology.

\section{Discussion}

In our study, lung cancer treatment possibilities and oneyear survival were analyzed according to the presence of LRTI at the time of bronchoscopy intervention. Interaction of LRTI and lung cancer outcome data is scarce, and our data demonstrated worse outcome in patients with lung malignancies, having LRTI at diagnosis. In the case of LRTI patient's ECOG performance status was significantly worse; consequently, patients had less therapeutic possibilities. This is in line with the Italian survey, confirming the 


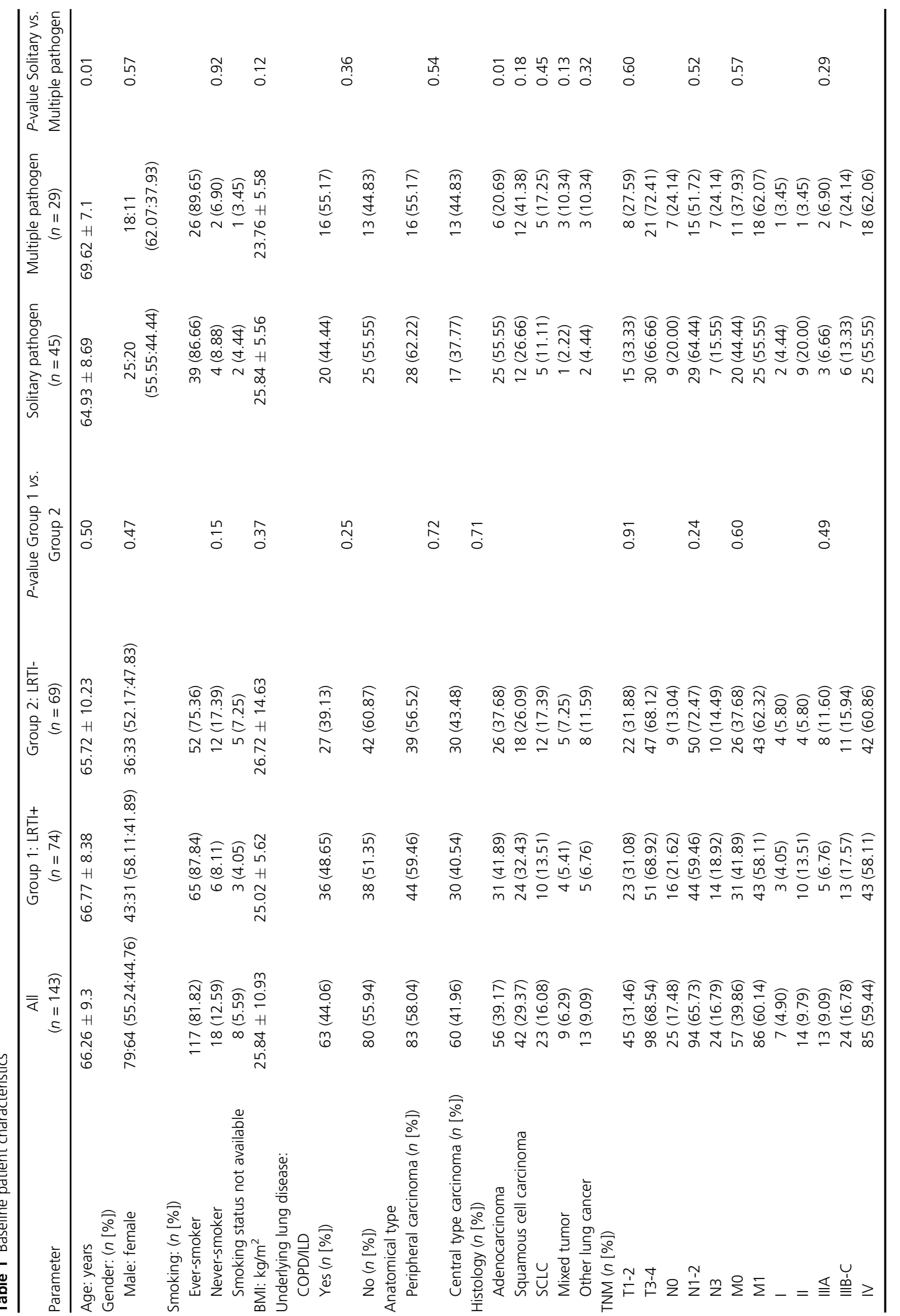




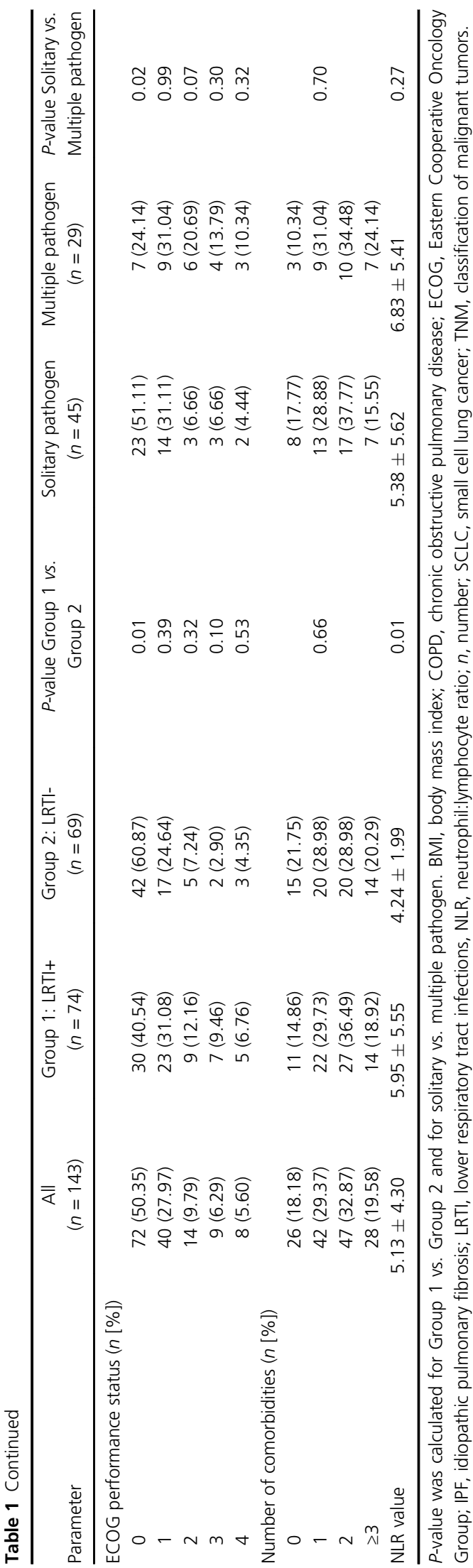

most common cause of patient exclusion from first-line chemotherapy, which is the poor ECOG performance status $(2-4) .{ }^{17}$ The ECOG performance status is a crucial predictive factor when allowing for treatment with chemotherapy, and the higher the number is connected with shorter survival as also noted in previous studies ${ }^{18,19}$ and confirmed in our analysis.

Similarly to other researches, the NLR was higher in patients with lung malignancy, associated with LRTI and lower in those with noninfectious cases. ${ }^{20}$ High NLR at diagnosis is an accepted prognostic marker of worse prognosis and therapy response for patients with lung cancer. ${ }^{21-23}$ As infections are often associated with high neutrophil count it could have contributed to the worse outcome in Group 1 (LRTI+) patients, most pronounced in patients with multiple pathogen infections.

The incidence of adenocarcinoma was the highest in our study population in agreement with international literature. ${ }^{4}$ Adenocarcinoma histology was associated with a more favorable outcome in our study population. Lung adenocarcinoma is mainly observed as a peripheral lesion, but in advanced stages, it also appears centrally, ${ }^{24}$ similarly to the other histological subtypes. ${ }^{25}$ Central carcinoma is readily associated with bronchial stricture and underlying pneumonia, which can advance in lung atelectasis. Consequently, microorganism colonization may evolve to infection. These known differences in the location could have contributed to the higher number of solitary pathogens $(80.65 \%$ vs. $46.51 \%)$ in adenocarcinoma patients; however, in our analysis, the locations of the tumors did not notably differ in the case of LRTI.

Patients with LRTI had worse one-year survival as compared to patients without an infection and significant increase of risk of one-year mortality. This is in line with previous observations, where patients with multiple pathogen LRTI got shorter median survival than patients with the solitary pathogen LRTI $(8.0$ vs. 15.0 months, $P=0.003){ }^{26}$

The lungs although previously considered sterile in health are regularly colonized with varied communities of microbes from the oropharynx and other locations. The most common Bacteroidetes and Firmicutes are the Prevotella, Veillonella and Streptococcus spp. Microbiota of the lung which mostly correspond to those of the mouth than of other body sites. In cases of respiratory tract inflammation, intra-alveolar catecholamines and inflammatory cytokines advance the growth of selected bacterial species (e.g., P. aeruginosa, S. pneumoniae, Staphylococcus aureus, Burkholderia cepacia complex). ${ }^{27}$

The most predominant pathogen in our lung cancer patients were Candida albicans, pursued by $H$. influenzae, S. aureus, S. pneumoniae and Enterobacter spp. These pathogens have been regularly recognized in lung infections, 
Table 2 LRTI pathogens in bronchoscopic samples at the time of cancer diagnosis

\begin{tabular}{|c|c|c|c|c|c|c|}
\hline Pathogen & $\begin{array}{l}\text { Group } 1 \text { LRTI } \\
+(n=74)\end{array}$ & $\begin{array}{l}\text { Adenocarcinoma } \\
\qquad(n=31)\end{array}$ & $\begin{array}{c}\text { Squamous cell } \\
\text { carcinoma }(n=24)\end{array}$ & $\begin{array}{c}\text { SCLC } \\
(n=10)\end{array}$ & $\begin{array}{c}\text { Other lung } \\
\text { cancer }(n=9)\end{array}$ & $\begin{array}{c}P- \\
\text { value }\end{array}$ \\
\hline Aerobic ( $n$ [\%]) & $49(55.06)$ & $21(60.00)$ & $16(59.26)$ & $7(58.33)$ & $5(33.33)$ & 0.32 \\
\hline Anaerobic ( $n[\%])$ & $14(15.73)$ & 5 (14.29) & $4(14.81)$ & $2(16.66)$ & $3(20.00)$ & 0.96 \\
\hline Fungal (n [\%]) & $26(29.21)$ & $9(25.71)$ & $7(25.93)$ & $3(25.00)$ & $7(46.66)$ & 0.44 \\
\hline $\begin{array}{l}\text { Solitary pathogen } \\
\qquad(n[\%])\end{array}$ & $45(60.81)$ & $25(80.65)$ & $12(50.00)$ & $5(50.00)$ & $3(33.33)$ & 0.02 \\
\hline $\begin{array}{l}\text { Multiple pathogen } \\
\qquad(n[\%])\end{array}$ & 29 (39.19) & $6(19.35)$ & $12(50.00)$ & $5(50.00)$ & $6(66.66)$ & \\
\hline
\end{tabular}

$P$-value was calculated for different cancer types in Group 1. LRTI, Lower respiratory tract infections; $n$, number; SCLC, small cell lung cancer.

Table 3 Oncotherapy in patients with pulmonary malignancy

\begin{tabular}{|c|c|c|c|c|c|c|c|}
\hline Oncotherapy & $\begin{array}{c}\text { All } \\
(n=143)\end{array}$ & $\begin{array}{c}\text { Group 1: } \\
\text { LRTI+ } \\
(n=74)\end{array}$ & $\begin{array}{c}\text { Group 2: } \\
\text { LRTI- }(n=69)\end{array}$ & $\begin{array}{c}P \text {-value } \\
\text { Group } 1 \text { vs. } \\
\text { Group } 2\end{array}$ & $\begin{array}{c}\text { Solitary } \\
\text { pathogen } \\
(n=45)\end{array}$ & $\begin{array}{l}\text { Multiple } \\
\text { pathogen } \\
(n=29)\end{array}$ & $\begin{array}{l}P \text {-value Solitary vs. } \\
\text { multiple pathogen }\end{array}$ \\
\hline $\begin{array}{l}\text { Curative intent surgery+/- } \\
\text { chemo/radiotherapy }(n[\%])\end{array}$ & $19(13.29)$ & $11(14.86)$ & $8(11.60)$ & 0.56 & $10(22.22)$ & $1(3.45)$ & 0.02 \\
\hline $\begin{array}{l}\text { Chemo-/immune-/target } \\
\text { therapy }(n[\%])\end{array}$ & $62(43.36)$ & 25 (33.78) & $37(53.62)$ & 0.02 & $15(33.33)$ & $10(34.48)$ & 0.91 \\
\hline Chemo + radiotherapy $(n[\%])$ & $16(11.19)$ & $4(5.41)$ & $12(17.39)$ & 0.02 & $2(4.44)$ & $2(6.90)$ & 0.64 \\
\hline Radiotherapy ( $n[\%])$ & $5(3.49)$ & $5(6.76)$ & 0 & Not valid & $2(4.44)$ & $3(10.34)$ & 0.32 \\
\hline $\operatorname{BSC}(n[\%])$ & $34(23.78)$ & $24(32.43)$ & $10(14.49)$ & 0.01 & $11(24.44)$ & $13(44.83)$ & 0.06 \\
\hline $\begin{array}{l}\text { Lost from medical attendance } \\
\qquad(n[\%])\end{array}$ & $7(4.89)$ & $5(6.76)$ & $2(2.90)$ & 0.28 & $5(11.11)$ & 0 & Not valid \\
\hline
\end{tabular}

$P$-value was calculated for Group 1 vs. Group 2 and for Solitary vs. multiple pathogen. BSC, best supportive care; LRTI, lower respiratory tract infections; $n$, number.

but the incidence of the microorganisms is different in recent studies, where the isolates of Enterobacter spp. (40.86\%), followed by S. aureus (21.51\%), H. influenzae (16.13\%) and S. pneumoniae (7.53\%) were recorded. ${ }^{28}$ The nonfermenting Gram-negative bacteria were Pseudomonas spp. (6.45\%) and Acinetobacter spp. (3.23\%). Among fungal species, the most common was Candida albicans $(63.77 \%)^{28,29}$

Infections increase the incidence of several malignancies (e.g., Human papillomavirus types 6 and 11 DNA sequences in cervical cancers, Helicobacter pylori infection in colorectal carcinoma). ${ }^{30,31}$ Lung cancer often evolves in damaged lungs (e.g., COPD, emphysema, IPF). ${ }^{7,8}$ In these lung diseases, mucociliary abnormality can grant mutagens from the smoke or further air pollution longer contact period at these locations, promoting the progress of pulmonary malignancy formation..$^{32}$ Constant irritation, caused by airway obstruction and the imbalance among oxidants and antioxidants may lead to DNA changes. ${ }^{33}$ The incidence of pulmonary malignancy in patients with IPF $(4.8 \%$ to $48 \%)$ is significantly higher than in patients without IPF $(2.0 \%$ to $6.4 \%){ }^{34,35}$ The mechanism of increased cancer development in IPF might be associated with increased inflammatory reaction, cell damage, abnormal fibroblast production and the activation of specific signaling pathways (e.g., Wnt $/ \beta$-catein). ${ }^{36-39}$ In our data set, about half of the patients had a significant underlying lung disease (COPD/IPF); however, this was not associated with differences in patients' characteristics of histology in the presence of LRTI.

In conclusion, LRTI, detected in bronchial samples at the time of diagnosis of lung malignancies influences the treatment options and outcome of these patients. Our data confirmed that LRTI+ patients had a worse ECOG performance status, withholding several treatment possibilities and so resulting in lower one-year survival. Patients with multiple pathogen LRTI were particularly less eligible for oncotherapy; however, no differences in stage, cancer histology subtype, gender or age were noted.

Our data emphasize that more attention should be given to LRTI and its treatment in lung cancer patients. The pathogen profile described in our series may assist with the selection of empiric treatment and hopefully decrease the observed risk of one-year mortality. Treatable threats are 
(a)

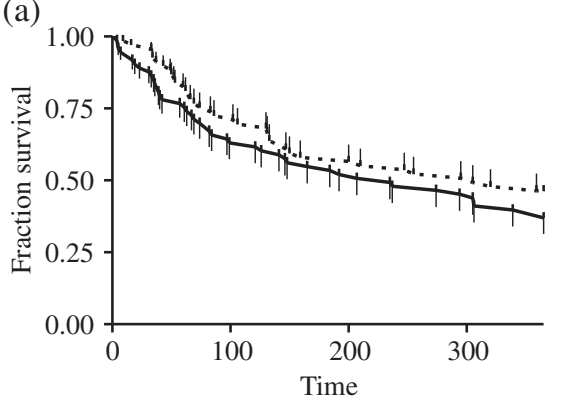

(b)

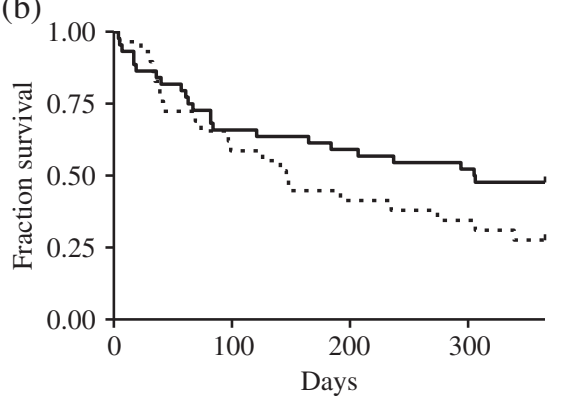

Figure 2 One-year survival of patients with pulmonary malignancy according to the presence of LRTI (a) (-) Group 1 (LRTI+), and (-----) Group 2 (LRTI-) and solitary and multiple pathogen LRTI (b) (----) Multiple pathogen (LRTI+), and (-) Solitary pathogen (LRTI+).

Table 4 Risk factors for one-year mortality

\begin{tabular}{lrrr}
\hline One-year mortality & OR & \multicolumn{1}{c}{ Cl 95\% } & $P$-value \\
\hline LRTI & 1.19 & $0.62-2.28$ & $>0.05$ \\
LRTI with multiple pathogen & 2.72 & $1.01-6.81$ & 0.04 \\
LRTI with solitary pathogen & 1.19 & $0.45-1.640$ & $>0.05$ \\
Male gender & 4.04 & $2.03-8.04$ & $<0.01$ \\
Nonadenocarcinoma & 2.26 & $1.15-4,56$ & 0.02 \\
Ever-smoker & 2.89 & $0.87-8.88$ & 0.09 \\
ECOG performance status 1 & 11.87 & $4.12-33.78$ & $<0.01$ \\
ECOG performance status $\geq 2$ & 30.00 & $5.23-313.00$ & $<0.01$ \\
\hline
\end{tabular}

ECOG, Eastern Cooperative Oncology Group; LRTI, lower respiratory tract infection. [Correction added on 25 July 2019, after first online publication: in Table 4, 'One-year survival' in first column has been corrected to 'One-year mortality'].

important elements to improve therapy and survival of this special patient population.

\section{Acknowledgments}

The manuscript has been professionally edited and proofread by the proof reading service of Semmelweis University.

\section{Disclosure}

There are no conflicts of interest.

\section{References}

1 Albano JD, Ward E, Jemal A et al. Cancer mortality in the United States by education level and race. JNCI J Natl Cancer Inst 2007; 99: 1384-94. https://doi.org/10.1093/jnci/ djm127.

2 Pang $\mathrm{HH}$, Wang $\mathrm{X}$, Stinchcombe TE et al. Enrollment tTrends and dDisparity aAmong pPatients wWith lLung cCancer in National Clinical Trials, 1990 to 2012. J Clin Oncol 2016; 34: 3992-9. https://doi.org/10.1200/JCO.2016. 67.7088.

3 Bray F, Ferlay J, Soerjomataram I, Siegel RL, Torre LA, Jemal A. Global cancer statistics 2018: GLOBOCAN estimates of incidence and mortality worldwide for 36 cancers in 185 countries. CA Cancer J Clin 2018; 68: 394-424. https://doi.org/10.3322/caac.21492.

4 Blandin Knight S, Crosbie PA, Balata H, Chudziak J, Hussell T, Dive C. Progress and prospects of early detection in lung cancer. Open Biol 2017; 7: 170070. https://doi.org/10. 1098/rsob.170070.

5 Walter JE, Heuvelmans MA, de Bock GH et al. Relationship between the number of new nodules and lung cancer probability in incidence screening rounds of CT lung cancer screening: The NELSON study. Lung Cancer 2018; 125: 103-8. https://doi.org/10.1016/j.lungcan.2018.05.007.

6 Janssen-Heijnen MLG, Maas HAAM, Houterman S, Lemmens VEPP, Rutten HJT, Coebergh JWW. Comorbidity in older surgical cancer patients: Influence on patient care and outcome. Eur J Cancer 2007; 43: 2179-93. https://doi. org/10.1016/j.ejca.2007.06.008.

7 Zhang X, Jiang N, Wang L, Liu H, He R. Chronic obstructive pulmonary disease and risk of lung cancer: A meta-analysis of prospective cohort studies. Oncotarget 2017; 8: 78044-56. https://doi.org/10.18632/oncotarget.20351.

8 Li J, Yang M, Li P, Su Z, Gao P, Zhang J. Idiopathic pulmonary fibrosis will increase the risk of lung cancer. Chin Med J (Engl) 2014; 127: 3142-9.

9 Mao Q, Jiang F, Yin R et al. Interplay between the lung microbiome and lung cancer. Cancer Lett 2018; 415: 40-8. https://doi.org/10.1016/j.canlet.2017.11.036.

10 Sarihan S, Ercan I, Saran A, Çetintas SK, Akalin H, Engin K. Evaluation of infections in non-small cell lung cancer patients treated with radiotherapy. Cancer Detect Prev 2005; 29: 181-8. https://doi.org/10.1016/j.cdp.2004.11.001.

11 Remiszewski P, Słodkowska J, Wiatr E et al. Infection as a main or additional cause of death in patients treated for small cell lung cancer. Pneumonol Alergol Pol 1999; 67: 347-53.

12 Torres VB, Azevedo LC, Silva UV et al. Sepsis-associated outcomes in critically ill patients with malignancies. Ann Am Thorac Soc 2015; 12: 150618124156002. https://doi.org/ 10.1513/AnnalsATS.201501-046OC.

13 Miller MR, Hankinson J, Brusasco V et al. Standardisation of spirometry. Eur Respir J 2005; 26: 319-38. https://doi.org/ 10.1183/09031936.05.00034805. 
14 Fruh M, De Ruysscher D, Popat S, Crino L, Peters S, Felip E. Small-cell lung cancer (SCLC): ESMO clinical practice guidelines for diagnosis, treatment and follow-up. Ann Oncol 2013; 24: vi99-vi105. https://doi.org/10.1093/ annonc/mdt178.

15 Planchard D, Popat S, Kerr K et al. Metastatic non-small cell lung cancer: ESMO clinical practice guidelines for diagnosis, treatment and follow-up. Ann Oncol Off J Eur Soc Med Oncol 2018; 29: iv192-237. https://doi.org/10.1093/annonc/ mdy275.

16 Postmus PE, Kerr KM, Oudkerk M et al. Early and locally advanced non-small-cell lung cancer (NSCLC): ESMO clinical practice guidelines. Ann Oncol 2017; 28: iv1-iv21. https://doi.org/10.1093/annonc/mdx222.

17 Gridelli C, Ardizzoni A, Barni S et al. Medical treatment choices for patients affected by advanced NSCLC in routine clinical practice: Results from the Italian observational "SUN" (survey on the lUng cancer maNagement) study. Lung Cancer 2011; 74: 462-8. https://doi.org/10.1016/j. lungcan.2011.04.011.

18 Minami S, Ogata Y, Ihara S, Yamamoto S, Komuta K. Outcomes and prognostic factors of chemotherapy for patients with locally advanced or metastatic pulmonary squamous cell carcinoma. Lung Cancer (Auckl) 2016; 7: 99-110. https://doi.org/10.2147/LCTT.S107560.

19 Minami S, Ogata Y, Ihara S, Yamamoto S, Komuta K. Retrospective analysis of outcomes and prognostic factors of chemotherapy for small-cell lung cancer. Lung Cancer (Auckl) 2016; 7: 35. https://doi.org/10.2147/LCTT.S100184.

20 Naess A, Nilssen SS, Mo R, Eide GE, Sjursen H. Role of neutrophil to lymphocyte and monocyte to lymphocyte ratios in the diagnosis of bacterial infection in patients with fever. Infection 2017; 45: 299-307. https://doi.org/10.1007/ s15010-016-0972-1.

21 Yao Y, Yuan D, Liu H, Gu X, Song Y. Pretreatment neutrophil to lymphocyte ratio is associated with response to therapy and prognosis of advanced non-small cell lung cancer patients treated with first-line platinum-based chemotherapy. Cancer Immunol Immunother 2013; 62: 471-9. https://doi.org/10.1007/s00262-012-1347-9.

22 Unal D, Eroglu C, Kurtul N, Oguz A, Tasdemir A. Are neutrophil/lymphocyte and platelet/lymphocyte rates in patients with non-small cell lung cancer associated with treatment response and prognosis? Asian Pac J Cancer Prev 2013; 14: 5237-42.

23 Yin Y, Wang J, Wang X et al. Prognostic value of the neutrophil to lymphocyte ratio in lung cancer: A metaanalysis. Clinics 2015; 70: 524-30. https://doi.org/10.6061/ clinics/2015(07)10.

24 Moon Y, Lee KY, Sung SW, Park JK. Differing histopathology and prognosis in pulmonary adenocarcinoma at central and peripheral locations. J Thorac Dis 2016; 8: 169-77. https://doi.org/10.3978/j.issn.2072-1439.2016.01.15.

25 Lemjabbar-Alaoui H, Hassan OU, Yang Y-W, Buchanan P. Lung cancer: Biology and treatment options. Biochim
Biophys Acta 2015; 1856: 189-210. https://doi.org/10.1016/j. bbcan.2015.08.002.

26 Qiao D, Wang Z, Lu Y, Wen X, Li H, Zhao H. A retrospective study of risk and prognostic factors in relation to lower respiratory tract infection in elderly lung cancer patients. Am J Cancer Res 2015; 5: 423-32.

27 Dickson RP, Erb-Downward JR, Martinez FJ, Huffnagle GB. The microbiome and the respiratory tract. Annu Rev Physiol 2016; 78: 481-504.

28 Szymankiewicz M, Kowalewski J, Dancewicz M. Bacteriological and mycological analysis of material taken from lower respiratory tract in patients with malignancy. Pol Merkur Lekarski 2006; 21: 218-22.

29 Watanabe A, Nakai Y, Saito J et al. Clinical significance of respiratory infections associated with lung cancer patients. Nihon Kyobu Shikkan Gakkai Zasshi 1992; 30: 1250-6.

30 Gissmann L, Wolnik L, Ikenberg H, Koldovsky U, Schnürch HG, zur Hausen H. Human papillomavirus types 6 and 11 DNA sequences in genital and laryngeal papillomas and in some cervical cancers. Proc Natl Acad Sci U S A 1983; 80: 560-3.

31 Abbass K, Gul W, Beck G, Markert R, Akram S. Association of Helicobacter pylori infection with the development of colorectal polyps and colorectal carcinoma. South Med J 2011; 104: 473-6. https://doi.org/10.1097/SMJ. 0b013e31821e9009.

32 Åstrand ABM, Hemmerling M, Root J et al. Linking increased airway hydration, ciliary beating, and mucociliary clearance through ENaC inhibition. Am J Physiol Lung Cell Mol Physiol 2015; 308: L22-32. https://doi.org/10.1152/ ajplung.00163.2014.

33 Caramori G, Casolari P, Cavallesco GN, Giuffrè S, Adcock I, Papi A. Mechanisms involved in lung cancer development in COPD. Int J Biochem Cell Biol 2011; 43: 1030-44. https:// doi.org/10.1016/j.biocel.2010.08.022.

34 Wells C, Mannino DM. Pulmonary fibrosis and lung cancer in the United States: Analysis of the multiple cause of death mortality data, 1979 through 1991. South Med J 1996; 89: 505-10.

35 Ma Y, Seneviratne CK, Koss M. Idiopathic pulmonary fibrosis and malignancy. Curr Opin Pulm Med 2001; 7: 278-82.

36 Hoyne GF, Elliott H, Mutsaers SE, Prêle CM. Idiopathic pulmonary fibrosis and a role for autoimmunity. Immunol Cell Biol 2017; 95: 577-83. https://doi.org/10.1038/icb. 2017.22.

37 Ballester B, Milara J, Cortijo J. Idiopathic pulmonary fibrosis and lung cancer: Mechanisms and molecular targets. Int $J$ Mol Sci 2019; 20: 593. https://doi.org/10.3390/ijms20030593.

38 Takahashi T, Munakata M, Ohtsuka Y et al. Expression and alteration of ras and $\mathrm{p} 53$ proteins in patients with lung carcinoma accompanied by idiopathic pulmonary fibrosis. Cancer 2002; 95: 624-33. https://doi.org/10.1002/cncr.10708.

39 Bowley E, O'Gorman DB, Gan BS. $\beta$-Catenin signaling in fibroproliferative disease. J Surg Res 2007; 138: 141-50. https://doi.org/10.1016/j.jss.2006.07.026. 